
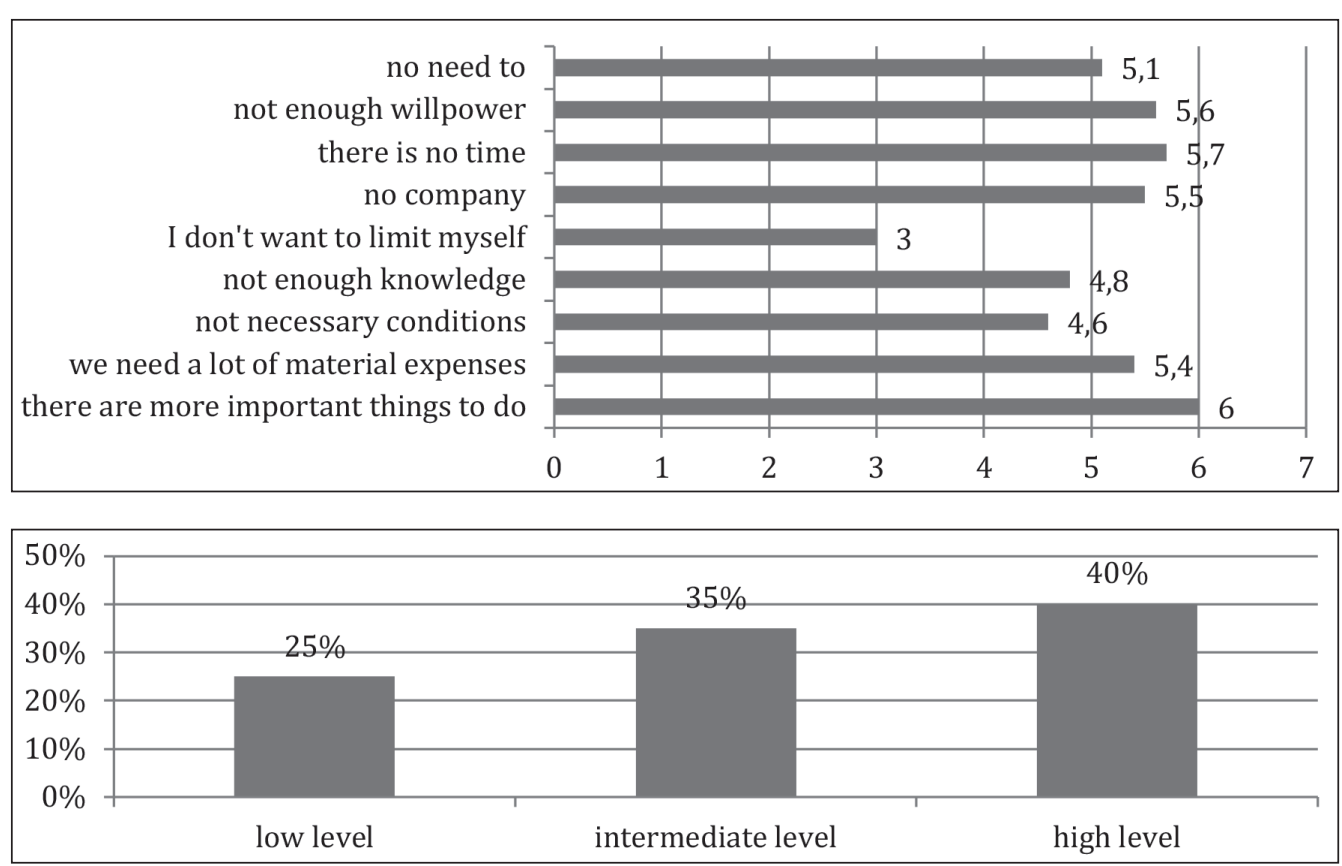

Fig. 6. Linear histogram of the causes of insufficient and irregular health care

Fig.7. Histogram of levels of motivation for a healthy lifestyle

Table I. Levels of motivation for a healthy lifestyle in different areas of health

\begin{tabular}{ccccc}
\hline Indicators & Spiritual health & Social health & Psychological health & Physical health \\
\hline Low level & $6 \%$ & $6 \%$ & $3 \%$ & $6 \%$ \\
\hline Average-low level & $32 \%$ & $13 \%$ & $23 \%$ & $12 \%$ \\
\hline Average level & $31 \%$ & $35 \%$ & $37 \%$ & $37 \%$ \\
\hline Average-high level & $19 \%$ & $21 \%$ & $25 \%$ & $31 \%$ \\
\hline High level & $12 \%$ & $25 \%$ & $12 \%$ & $14 \%$ \\
\hline
\end{tabular}

$(\mathrm{n}=20)$ - at average- high level; 13\% $(\mathrm{n}=12)$ respondents have an average-low level of formation; high level is observed in $25 \%(\mathrm{n}=23)$; low in $6 \%(\mathrm{n}=6)$.

- in the mental aspect, motivation for a healthy lifestyle, a high level is observed in $12 \%(\mathrm{n}=11)$; average-high in $25 \%(\mathrm{n}=23)$; average in $37 \%(\mathrm{n}=35)$; average-low in $23 \%(n=22)$; low level in $3 \%(n=3)$ of undergraduates. - in the physical aspect $37 \%(\mathrm{n}=35)$ of respondents have an average level of motivation for a healthy lifestyle; $31 \%$ $(\mathrm{n}=29)$ - average-high level; $12 \%(\mathrm{n}=11)$ - average-low; $14 \%(n=13)$ have a high level of motivation; $6 \%(n=6)$ have a low level of motivation in the physical aspect.

In Fig. 7 one graphically presents the general level of motivation for a healthy lifestyle among undergraduates. A high level includes average-high levels, and a low level includes average-low levels.

The analysis of the obtained data gives grounds to conclude that in general, i.e. in the context of all four components of health, the formation of motivation for a healthy lifestyle in respondents is as follows: a high level is observed in $40 \%(\mathrm{n}=38)$; average in $35 \%(\mathrm{n}=33)$ and low in $25 \%(\mathrm{n}=23)$ of applicants of the second (master's) level of higher education.

Thus, based on the analysis of the characteristics of respondents' values of health, we can conclude on the importance of health and development in the hierarchy of values. Among the terminal values, health ranks $3^{\text {rd }}$ and development ranks $4^{\text {th }}$ place in the overall sample. Based on the obtained data, we can conclude that such values as health and development in the hierarchy of values of respondents occupy a fairly high priority, and are part of the motivational core.

Sufficient level of motivation to maintain and strengthen health, which is manifested in the understanding of the importance of health for success and awareness of the need to take care of one's health, however at this stage the motivation is not internal but depends on external facts (parents, friends, conditions, finances, etc.). Health values are at the forefront of the personality hierarchy. It should be noted that the level of motivation for a visual lifestyle is more pronounced in the physical and social aspects of health, in the spiritual aspect - the average-low level of motivation for a healthy lifestyle prevails. The need for a healthy lifestyle is quite stable, but is mostly external.

Taking into account the results of quantitative and qualitative analysis of the real state of formation of a healthy lifestyle, the pedagogical tools of health orientation based on interactive forms and methods of forming a healthy lifestyle which are grounded on the partner subject-subject interaction of the teacher and students, on their dialogue, polylogue and cooperation, were substantiated and developed. 
In our opinion, the appropriate interactive method of forming a healthy lifestyle is the method of analysis of specific situations or case-study. Case is a description of a real life situation, containing accompanying facts, opinions, judgments, which are based on solving a problem. The case is always based on a contradictory situation that has actually occurred or may arise. So the essence of this method is that the information is presented in the form of a problem, and knowledge is acquired in the process of analytical activities. This method is effective in forming a valued attitude to health, the ability to analyze your lifestyle; to form one's own position on certain events of other people's way of life.

In the process of experimental work, the method of situation analysis was used on the material of real confessions of drug addicts [14] in order to cultivate drug resistance as a psychological basis for preventing bad habits and forming an attitude to a healthy lifestyle. In working with situations-confessions it is possible to use the following algorithm: 1. Familiarity with the situation and its perception. 2. Interpretation and understanding of the situation in the following aspects: at what age, as well as for what reasons the first acquaintance with drugs took place; how drug addiction developed and how it manifested; analysis of the consequences of drug addiction; whether it is possible to defeat drugs and in what way. 3. Formation of attitude to the situation. 4. Representation of one's version of the solution of the problem.

An appropriate interactive method of forming a healthy lifestyle for students of a modern university is "brainstorming". Its essence is to formulate as many ideas as possible related to the problem, which is discussed and carried out in two stages: 1. Formulation of certain hypotheses $(5-10$ minutes, during which participants express their opinions, which are recorded without comments and assessments). 2 . Evaluation of ideas (10 - 15 minutes). At this stage, similar ideas are classified, discussed and evaluated, unproductive ideas are deleted from the general list.

Here is an example of using the method of brainstorming in the formation of motives and needs of rational eating behavior, which is a set of forms of human behavior, including mode (frequency, distribution over time), pace (speed) of food intake, predominant consumption of certain foods, motives and reasons to food intake, subjective attitude to the process of nutrition [15]. We have proposed and tested brainstorming "The impact of eating behavior on social, mental and physical health". The content of the brainstorming was to discuss a number of issues according to the method of I. Malkina-Pykh [16], among which are the following questions:

1. How and when is our eating behavior formed?

2. Why can it be disturbed?

3. What are the types of eating disorders that lead to overweight?

4. How to recognize in the body a feeling of hunger, and how - appetite?

5 . How is the ideal body weight calculated?

6 . What is obesity?
7. How is eating behavior regulated?

8. How does medicine explain the occurrence of excess weight?

9. What is the nutrition strategy of a slender person?

10 . What is your diet stereotype?

Thus, the above interactive methods of forming a healthy lifestyle have significant potential for the formation of axiological aspects of a healthy lifestyle, personal subject position, critical thinking, skills of interaction, cooperation, partnership.

An essential component of the pedagogical tools of health orientation are the methods of reflexively oriented on self-knowledge and self-awareness. Since important aspects of a healthy lifestyle are the reflection of health, self-regulation of behavior, adequate self-assessment of health as the ability to self-control and self-correction, based on the mechanism of reflection. In the process of formative work we used methods of self-knowledge of reflexive orientation, developed in the study of V. Zhelanova [17]:

"My portrait in the rays of the sun"

Task content: Write your name in the center of the solar circle or draw (paste) your portrait. Then write along the rays all your qualities that are associated with the implementation or violation of a healthy lifestyle. Try to have as many rays as possible.

"What am I"

Task content: Write in two columns your characteristic qualities. In the first column - the qualities that will contribute, in your opinion, the implementation of a healthy lifestyle. In the second column - the qualities that may hinder it.

An alternative to the previous task may be to write an essay "What would I like to change in my lifestyle?".

A similar alternative may be a method of creating an attractive image of a healthy person and an ideal image of oneself (imaginary, schematic, graphic, computer).

The purpose of scientific intelligence was realized. The results of the diagnosis showed that $36 \%(n=34)$ of undergraduates take care of their health insufficiently or irregularly. This objective circumstance necessitates the further search for new tools for the formation of values to a healthy lifestyle, motivation to improve it, a stable attitude to the implementation of the canons of a healthy lifestyle. The outlined problem acquires special weight in the conditions of distribution in our society of such negative phenomena, as a passive way of life, mass obesity, smoking, alcoholism and drug addiction.

\section{CONCLUSIONS}

Theoretical understanding and the results of the diagnostic study of the value-motivational component of a healthy lifestyle (according to the following methods: M. Rokich's "Value orientations" method, R. Berezivska's questionnaire "Attitude to health" (value-motivational scale), questionnaire "Motivational component of a healthy lifestyle" (N. Voloshko, V. Rybalka), which was attended by 94 applicants for the second (master's) level of higher education in the specialties 
011 Educational, pedagogical sciences (educational and professional program 011.00.01 "Higher school pedagogy"), 012 Preschool education and 013 Primary education of the Pedagogical Institute of Borys Grinchenko Kyiv University, proved the relevance, feasibility and necessity of clarifying the real state of formation of value components of a healthy lifestyle of university students and development of pedagogical tools for health, containing interactive forms and methods of healthy lifestyle, as well as reflexive exercises with orientations that stimulate the development of self-esteem and self-regulation of a healthy lifestyle.

The aspect of the problem related to the diagnosis of the real state of formation of cognitive and activity components of a healthy lifestyle of university students and to the improvement of pedagogical tools of health orientation needs further development.

\section{REFERENCES}

1. Amosov N.M. Encyklopedia zdoroviya. Algoritm zdoroviya [Amosov's Encyclopedia. Health algorithm]. Donetsk. Stalker. 2002; 590. (in Ukrainian).

2. Bulych E.G. Valeologiya. Teorytychni osnovy valeologii [Valeology. Theoretical foundations of valeology]: textbook for students of pedagogical educational institutions of postgraduate education. Institute of Content and Teaching Methods. Kyiv. IZMH; 1997, 224. (in Ukrainian).

3. Potashnyuk R.Z. Psyhogigiena [Psychohygiene]: Textbook. Manual. Volyn. state Univ. of L. Ukrainka. Lutsk. Nadstrya. 2000; 62. (in Ukrainian).

4. YakimenkoS.I., OksenchukN.V. Formyvannya kultury zdorovogo sposoby zhyttya ychniv osnovnoi shkoly y pozaklasniy roboti. Navchalnometodychnyi posibnyk [Formation of a culture of healthy lifestyle of primary school students in extracurricular activities. Educational and methodical manual]. Kyiv. Slovo Publishing House; 2012, 288. (in Ukrainian).

5. Bashavets N.A. Teoretyko-motodologichni zasady formyvannya kultury zdorovyazberezhennya yak svitoglyadnoi orientacii studentiv vyschyh ekotomichnyh navchalnych zakladiv [Theoretical and methodological principles of forming a culture of health care as a worldview orientation of students of higher economic educational institutions]: author's dissertation of a candidate of Pedagogical Science: special. 13.00.04 "Theory and methods of professional education". Cherkasy. 2012; 40.

6. Palamar B.I., Vaskivska H.O., Palamar S.P. Didacticaspects of cognition of human as a bio-psycho-socio-cultural personality. Wiadomości Lekarskie. 2017; 70(5): 959-963.

7. Gruzieva T.S., Galiienko L.I., Pelo I. M. et al. Health and lifestyle of students' youth: status, problems and ways of solution. Wiadomości Lekarskie. 2018; 71 (9): 1753-1758.

8. Savchenko 0.Ya. Yakist I variatyvnist shkilnykh pidrychnukiv yak ymova zaprovadzhennya derzhavnykh standartiv pochatkovoi osvity [Quality and variability of school textbooks as a condition for the introduction of state standards of primary education]. Primary school. 2001;8:10 - 12 .

9. Romanova N.F. Formyvannya zdorovogo sposoby zhyttya yak sychasna strategiya protydii socialno nebezpechnym hvorobam sered ditei ta molodi: monographiya [Formation of a healthy lifestyle as a modern strategy to combat socially dangerous diseases among children and youth: a monograph]. Counteracting socially dangerous diseases: the study of Ukrainian experience. Kyiv. Pylsary; 2010, 39 - 48.
10. Uznadze D. Mindset Psychology. St. Petersburg; 2001, 414.

11. Rokeach M. The nature of human values. N.Y. Free Press; 1973, 854.

12. Berezovskaya R.A. Attitude to health. Health psychology. St. Petersburg. 2003;100-110.

13. Voloshko N.I. Psyhologiya stanovlennya zdorovogo sposoby shyttya v navchalno-vychovnomy procesi [Psychology of formation of a healthy way of life in educational process]: program-practicum: [scientific method. textbook] Kyiv. Scientific world. $2012 ; 99$.

14. Baymukhametov S. Zolotye sny; ispovedi narkomanov [Golden dreams: confessions of drug addicts]. booksonline.com.ua/review. php?book=116659. (in Russian).

15. Vakhmistrov A.V. Naryshenie pischevogo povedeniya pri cerebralnom ozhyrenii [Eating disorders in cerebral obesity]: Abstract of dissertation of candidate of Medical Studies. StP. 2006; 24.

16. Malkina-Pykh I. G. Lychniy ves. Osvoboditsya i zabyt'. Navsegda [Overweight. Free yourself and forget. Forever]. Moscow. Eksmo. 2012; 252. (in Russian).

17. Zhelanova V.V. Teoriya technologiya conteksnogo navchannya maibutnyogo vchytelya pochatkovych klasiv [Theory and technology of contextual education of the future primary school teacher]: monograph. Luhansk. Taras Shevchenko Lviv.

\section{ORCID and contributionship:}

Dmytro V. Zhelanov: 0000-0002-9017-6960 A, B,D

Borys I. Palamar: 0000-0003-2510-0713 A, B, C, D, E, F

Tetiana S. Gruzieva: 0000-0001-9254-7561 A, B, C, D, E, F

Victorija V. Zhelanova : 0000-0001-9467-1080 A, B,D

Inna V. Leontieva: 0000-0002-8084-1912 ${ }^{A, B, D}$

Maryna A. Yepikhina: 0000-0003-0199-8186 A, B,D

\section{Conflict of interest:}

The Authors declare no conflict of interest

\section{CORRESPONDING AUTHOR \\ Borys I. Palamar \\ Bogomolets National Medical University, 13 Taras Shevchenko Blvd., 01601 Kyiv, Ukraine \\ tel: +380672387654 \\ e-mail:palamar.bi@ukr.net}

Received: 19.12 .2020

Accepted: 30.03 .2021

A - Work concept and design, B - Data collection and analysis, C - Responsibility for statistical analysis, D-Writing the article, E-Critical review, $\mathbf{F}$ - Final approval of the article 


\title{
PSYCHOPHYSIOLOGICAL STUDY OF PRIMARY SCHOOL STUDENTS DEPENDING ON GENDER IN THE DYNAMICS OF THE SCHOOL YEAR AND THE ACTIONS OF PARENTS TO MAINTAIN AND STRENGTHEN THE HEALTH
}

DOI: 10.36740/WLek202105107

\author{
Heorhii M. Danylenko ${ }^{1,2}$, Leonid V. Podrigalo ${ }^{1,3}$, Olena H. Avdiievska ${ }^{1,2}$, Iryna V. Redka², Oksana Ya. Mykhalchuk ${ }^{2}$ \\ "STATE INSTITUTION “INSTITUTE FOR CHILDREN AND ADOLESCENTS HEALTH CARE AT THE NATIONAL ACADEMY OF MEDICAL SCIENCES OF UKRAINE”, \\ KHARKIV, UKRAINE \\ 2V.N. KARAZIN KHARKIV NATIONAL UNIVERSITY, KHARKIV, UKRAINE \\ ${ }^{3}$ KHARKIV STATE ACADEMY OF PHYSICAL CULTURE, KHARKIV, UKRAINE
}

\begin{abstract}
The aim: Study of psychophysiological features of children depending on gender in the dynamics of the school year and the action of parents on preventive measures among primary school children

Materials and methods: The study of biological adaptation of primary school students was conducted in two stages among second-graders (children 7-8 years) in the dynamics of the week and year. A total of 46 children (24 girls and 22 boys). The psychophysiological part of the study included electroencephalography (EEG) recording to assess the individual characteristics of the nervous system and determine mental performance. The next step was to determine mental performance, which is one of the important criteria for the health of schoolchildren, which characterizes the relationship between the functional state of the child's body and learning load. The analysis of mental capacity was conducted at school with the permission of parents during the first school week and the last school week.

Results: Based on the recorded EEG, the average values of the peak frequencies in each lead in the five ranges were calculated. When comparing the average values of indicators recorded in the modes of quiet wakefulness and mental load (mental account) at the beginning of the year, using a nonparametric criterion of signs revealed significant $(p<0,05)$ differences between peak frequencies in the ranges $\beta_{1}$ and $\beta_{2}$. The average peak frequency in the $\beta_{1}$ range at rest $(14.3 \pm 0.5 \mathrm{~Hz})$ is higher than during mental stress $(13.8 \pm 0.4 \mathrm{~Hz})$. autonomy of regulation $(\mathrm{p}<0.01)$ in girls at the end of the school year is characterized by higher values. Analysis of data on the mental capacity of first-graders showed that the dynamics of the week among boys the number of traced signs increased from $(120.5 \pm 2.6)$ to $(122.3 \pm 4.8)$ signs, ( $p>0.05)$ by the end of the week , and had the largest number of signs on Wednesday (127.4 \pm 4.2 ) but had no significant difference

Conclusions: Preventive measures such as sleep and rest, walks in the fresh air aimed at promoting health can be the same for both girls and boys, but more attention and control over the implementation of these measures should be paid to boys.
\end{abstract}

KEY WORDS: primary school students, biological adaptation, parents and preventive measures, gender

Wiad Lek. 2021;74(5):1086-1092

\section{INTRODUCTION}

Education in elementary school is one of the critical periods of childhood, both in the socio-psychological and physiological terms. This period brings with it serious tests of the adaptive capabilities of the child's body. The child's usual way of life is changing, his place in the system of social relations, his usual sleep pattern, diet, rest regimen, time spent in the fresh air, and the psychoemotional load also increases. For children, this is not only new living conditions and activities, but new contacts, relationships, responsibilities. From the very first days, the junior school poses a number of tasks for the students, requires the maximum mobilization of intellectual and physical strength. However, not all children are ready for such changes $[1 ; 2]$.

Even first-graders with a sufficiently high level of intellectual development can hardly bear the load that school edu- cation obliges. In response to the new increased demands, children may complain of fatigue, headaches, irritability, tearfulness, sleep disturbance, children's appetite and body weight decrease. Difficulties of a psychological nature are formed, such as, for example, a feeling of fear, a negative attitude towards studies, a teacher, and a misconception about one's abilities and capabilities [3-8].

Daily training sessions require intense mental work, increased attention, focused work during lessons, relatively motionless body position and maintaining the correct working posture [4]. Chronic stress accompanying this process in the presence of other risk factors contributes to the development of maladjustment syndrome with the subsequent deterioration of the morphological and functional parameters of the organism of first-graders. Adapting to new conditions, the body mobilizes for this a system of 
adaptive reactions. This whole complex of phenomena is classified as an adaptation syndrome $[9,10]$.

Therefore, the successful adaptation of the child's body to the conditions of an educational institution is considered an important link in the subsequent formation of health and the preservation of its reserves in the future, and also helps parents to organize the correct mode of work and rest [2]. However, there are differences in the organization of prevention activities for girls and boys. For example, nutritional interventions should vary according to the gender of the child. Comparative analysis of fresh vegetables and fruits consumption also illustrates certain specific features of eating. Earlier we have already assumed that orientation on healthy eating differs depending on sex. These facts permit to assume great risk of vitamins' deficit, as well and mineral substances and food fibers in boys [11].

Research in the field necessitates some definition of what kind of involvement is at issue; some specification of which school outcomes are expected to be generated; some means of measuring or evaluating these desired outcomes and some means of analysis which affords warrantable conclusions about the impact of involvement on outcomes [12].

An urgent medical and social problem at present is the high prevalence among students of factors that are due to lifestyle - smoking, alcohol consumption, low physical activity, unhealthy diet, and determine the unfavorable prognosis of the health of the younger generation. A promising area for preserving and strengthening the health of children is the formation of a healthy lifestyle, for which the effective interaction of family and educational institution is of particular importance. However, there are currently no mechanisms for educational institutions to interact with families to promote student health. At the same time, strategies for forming a healthy lifestyle can be most effectively implemented in organized groups, among children and adolescents enrolled in educational institutions.

Note that the whole family, of course, does not guarantee the normal development of the adolescent's personality and social development, but creates more favorable conditions for this. And a single-parent family formed after a divorce is a risk factor for the development of the child's personality, regardless of whether parents understand that the family with all its attributes affects the child's psyche and subconsciously shapes its behavior [13-15].

\section{THE AIM}

Study of psychophysiological features of children depending on gender in the dynamics of the school year and the action of parents on preventive measures among primary school children

\section{MATERIALS AND METHODS}

The study of biological adaptation of primary school students was conducted in two stages among second-graders (children 7-8 years) in the dynamics of the week and year. A total of 46 children ( 24 girls and 22 boys). The psychophysiological part of the study included electroencephalography (EEG) re- cording to assess the individual characteristics of the nervous system and determine mental performance. EEG registration was performed in two modes - background (state of quiet vigilance) and during the performance of mental load (countdown in the mind). Examination and registration of EEG were performed in the laboratory of functional diagnostics of the State Institution "Institute of Child and Adolescent Health of the National Academy of Medical Sciences of Ukraine" with the permission of parents twice a year. To study the functional activity of the brain, computer electroencephalogram registration was used. To assess the emotional state of the subjects, a parallel EEG recording and heart rate variability (HRV) were performed. EEG recording was performed with eyes closed. After applying the electrodes, the subject spent some time in a chair in order to relax and calm down. The encephalographic session consisted of several events:

1) background recordings in a state of quiet vigilance in the absence of light and other extraneous stimuli. Each recording continued for $150 \mathrm{~s}$;

2) tests for opening and closing the eyes for $150 \mathrm{~s}(30 \mathrm{~s}$ before opening the eyes, 40-60 s with the eyes open, the rest of the time with the eyes closed);

3) functional load designed to perform successive mental operations, which causes a slight intellectual stress (countdown in the mind - from 1000, 999, etc.). Recording continued for 150 seconds.

HRV parameters were determined using the software package NeuroResearcher ${ }^{\circledast}$-Cardio-Tension-Test ${ }^{\oplus}$ (Institute Mi\&T LTD, Ukraine). Statistical and spectral indicators of HRV were calculated. Rhythmogram spectral analysis was performed using a fast Fourier transform [17].

The next step was to determine mental performance, which is one of the important criteria for the health of schoolchildren, which characterizes the relationship between the functional state of the child's body and learning load [18]. The analysis of mental capacity was conducted at school with the permission of parents during the first school week and the last school week. In modern conditions there is a complication of the educational process. The amount of information has increased, emotional loads have increased, and the level of motor activity of children and adolescents has sharply decreased. The study of the dynamics of mental performance with the subsequent development of medical and preventive measures allows to organize the learning process so as to ensure the best possible learning outcomes with favorable dynamics in the health of students.

At the meeting, the commission on bioethics and deontology of the SI "ICAHC NAMS" (№ 10 of October $26,2020)$ considered this work and it to be in line with the principles of the Helsinki Declaration adopted by the General Assembly of the World Medical Association (19642000), The Council of Europe Convention on Human Rights and Biomedicine (1997), the International Code of Medical Ethics (1983) and the laws of Ukraine.

The application package SPSS-17 and Microsoft ${ }^{\circ}$ Excel'2007 (license № d47646601451106a68cb and CMPJ6-YBX7P-CJPKF-62GPW-F) were used for statistical processing. 


\section{RESULTS}

For the first time, a psychophysiological study of students in the dynamics of the school year was conducted.

Peak frequency is one of the key parameters of EEG spectral analysis, which allows to assess the functional state of neurodynamic systems of the brain, the activity of which is reflected in the corresponding EEG ranges $\left(\delta, \theta, \alpha, \beta_{1}, \beta_{2}\right)$.

Based on the recorded EEG, the average values of the peak frequencies in each lead in the five ranges were calculated. When comparing the average values of indicators recorded in the modes of quiet wakefulness and mental load (mental account) at the beginning of the year, using a nonparametric criterion of signs revealed significant $(\mathrm{p}<0,05)$ differences between peak frequencies in the ranges $\beta_{1}$ and $\beta_{2}$ (Fig. 1). The average peak frequency in the $\beta_{1}$ range at rest $(14.3 \pm 0.5 \mathrm{~Hz})$ is higher than during mental stress $(13.8 \pm 0.4 \mathrm{~Hz})$ (Fig. 1).

It is known that the beta rhythm is inherent in the state of active vigilance. This rhythm is most pronounced in the frontal areas. At various types of intensive activity sharply amplifies and extends to other areas of a brain. Thus, the severity of $\beta$-rhythm increases with the presentation of a new unexpected stimulus, in a situation of attention, mental stress, emotional arousal [16]. It is possible that the study causes emotional stress in the child (fear of the study). This condition gradually passes in the process of EEG recording and the indicator decreases.

At the same time, a different dynamic is observed in the $\beta_{2}$ range. The mean peak frequency in the $\beta_{2}$ range at rest was lower $(21.6 \pm 0.5 \mathrm{~Hz})$ than during mental stress $(22.0 \pm 0.6 \mathrm{~Hz})$. It is possible that the increase in the peak frequency in the $\beta_{2}$ range reflects the mental stress during mental activity.

As follows from the analysis of the dominant frequencies in the EEG ranges at the end of the school year using the nonparametric criterion of signs in the studied states significantly $(\mathrm{p}<0.05)$ differ average values of the peak frequency only in the $\beta_{2}$ range (Fig. 2 ).

Based on the data obtained, some conclusions can be drawn. First, the studied children at the end of the school year are less emotionally responsive to the EEG study there is no paradoxical reaction in the $\beta_{1}$ range - there are no higher values of peak frequency in the registration of background activity compared to mental stress. Second, the values of the average peak frequency in the $\beta_{2}$ range at the end of the school year during mental activity, as well as at the beginning of the school year increase, but less significantly. This may indicate a less pronounced excitation of the systems involved in mental stress and indicate adaptation. Based on these indicators, it can be argued that meritocratic training does not cause pathological changes in cerebral activity.

Assessment of the degree of emotional stress and autonomic performance in children during training was performed using the analysis of heart rate variability (HRV) $[17 ; 19 ; 20]$. To analyze the dynamics of HRV in groups of boys and girls, the following indicators were selected: IA - Index of anxiety, ART - Anxiety reaction type [19], as well as indicators of the HRV parameter factor model [20] - main factors: F1 (reflects the severity of reflex integration, vegetative and humoral (homeostatic) mechanisms), F2 (reflects the degree of autonomy of regulation) and F3 (allows you to assess the degree of centralization of heart rate control).

The values of the anxiety index (anxiety) in boys had large individual differences and in a state of quiet wakefulness ranged from 55.7 to 454.7 . - at the beginning of the year, from 59.2 to 336.7 - at the end of the year. The same pattern was observed in girls (50.4-970.9 - at the beginning of the year, 69.9-776.9 - at the end of the year). The average level of stress in the girls was higher.

Preliminary analysis of the data showed a large variance, so not only the average values of boys and girls were calculated, but also the percentiles at 10 and $90 \%$.

The analysis and comparison of results were performed for indicators recorded at the beginning and end of the school year using non-parametric Mann-Whitney criteria (for independent samples - when comparing boys and girls) and Wilcoxon test - for dependent (when comparing boys at the beginning and end of the school year). year and girls at the same time) [16].

Comparison of HRV indicators recorded at the beginning of the school year and at the end of the school year did not reveal significant differences either among boys or among girls.

At the same time, significant differences were obtained between the studied indicators of boys and girls at the end of the school year (Fig. 3). These are the differences between the IA rates of boys and girls $(p<0.007)$ and ART $(\mathrm{p}<0.006)$. Girls have a higher level of emotional stress (IA) and activation of the sympathetic division of the autonomic nervous system (ART). (Fig. 3.)

Also, some of the main factors of HRV were significantly different (Fig. 4). F1, which reflects the severity of the integration of reflex, autonomic and humoral (homeostatic) mechanisms) $(p<0,03)$. Based on the physiological interpretation of this factor, which is formed by the variables obtained by correlation (CC0) and spectral (VLF, LF) analysis of RR intervals, lower than in boys, the eigenvalues of this factor indicate a weakening of the activity of cardiostimulatory and vasomotor centers, reducing the influence of higher levels of government for girls at the end of the school year. (Fig. 4.).

F2, which reflects the degree of autonomy of regulation $(\mathrm{p}<0.01)$ in girls at the end of the school year is characterized by higher values. This factor is formed by variables obtained as a result of correlation (CC1) and spectral (-HF, LF) analysis of RR intervals. Based on the physiological interpretation of factor F2, higher in girls than in boys, the eigenvalues of this factor indicate a large "dependence" of the autonomic control circuit on the activity of pacemaker and vasomotor centers, stronger control by higher levels of regulation and greater stress functioning of the cardiovascular system.

According to the F3 factor, which reflects the degree of centralization of heart rate management, no significant 

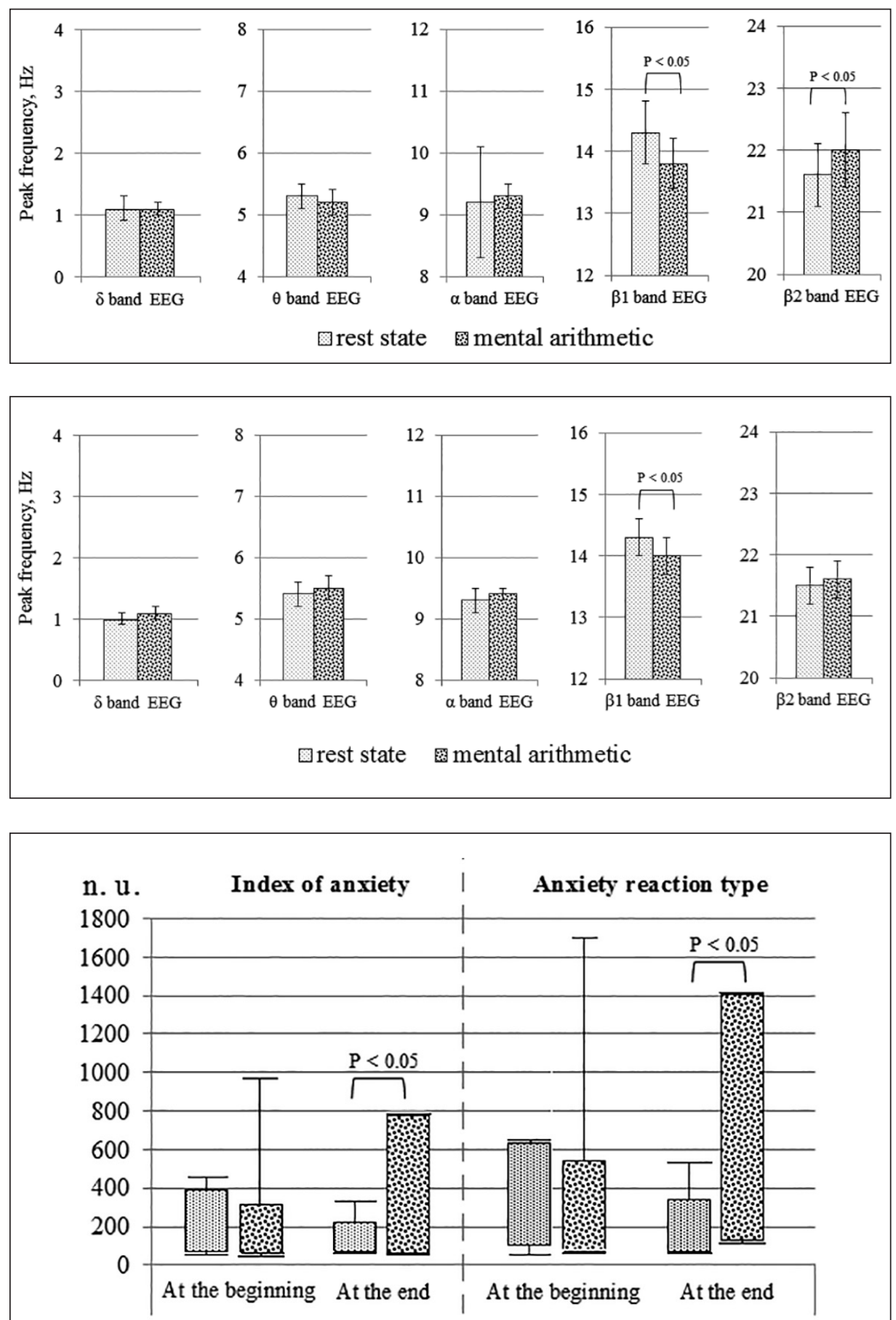

圆 boys 图 girls
Fig. 1. The changes of EEG bands peak frequency during the mental arithmetic at the beginning of the academic year

Fig. 2. The changes of EEG bands peak frequency during the mental arithmetic at the end of the academic year

Fig. 3. Gender differences in changes of anxiety level during the academic year

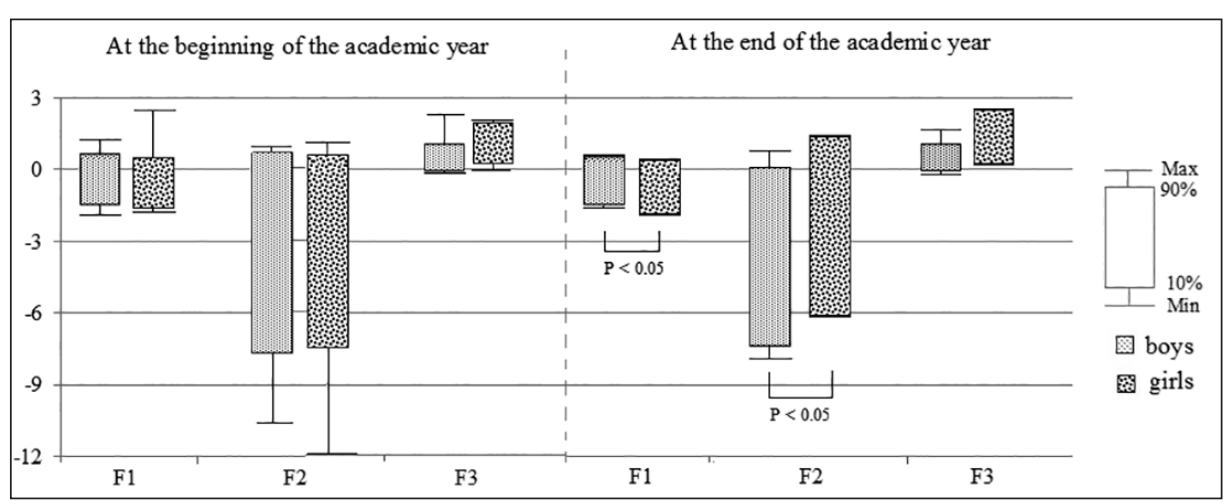

Fig. 4. Changes in levels of factors HRV during the academic year 
Table I. Quantitative and qualitative indicators of RP of second-graders during the week depending on gender at the beginning of the year, $\mathrm{M} \pm \mathrm{m}$, signs

\begin{tabular}{ccccc}
\hline \multirow{2}{*}{ Days week } & \multicolumn{2}{c}{ Quantitative indicators of MP } & \multicolumn{2}{c}{ Qualitative indicators of MP } \\
\cline { 2 - 5 } & Boys & Girls & Boys & Girls \\
\hline & $120,5 \pm 2,6$ & $121,0 \pm 3,0$ & $16,5 \pm 0,9 \cdot$ & $15,7 \pm 0,8 \cdot$ \\
\hline Monday & $117,7 \pm 3,3$ & $122,3 \pm 3,3$ & $15,3 \pm 0,9$ & $12,6 \pm 0,7$ \\
\hline Tuesday & $127,2 \pm 4,4$ & $127,4 \pm 4,2$ & $13,3 \pm 0,8$ & $11,9 \pm 0,8$ \\
\hline Wednesday & $120,6 \pm 4,8^{*}$ & $137,2 \pm 5,1^{*}$ & $14,7 \pm 1,1$ & $12,0 \pm 0,8$ \\
\hline Thursday & $122,3 \pm 4,8^{*}$ & $135,6 \pm 4,8^{*}$ & $14,4 \pm 0,8 \cdot$ & $11,6 \pm 0,7 \cdot$ \\
\hline Friday & $121,8 \pm 1,8$ & $128,1 \pm 1,8$ & $14,7 \pm 0,4$ & $12,8 \pm 0,3$ \\
\hline
\end{tabular}

${ }^{*} p<0,05-0,001$ the difference between the indicators of MP boys and girls;

$\cdot p<0,05-0,001$ the difference in MP during the week

Table II. Quantitative and qualitative indicators of $\mathrm{RP}$ of second-graders during the week depending on gender at the end of the year, $\mathrm{M} \pm \mathrm{m}$, signs

\begin{tabular}{ccccc}
\hline \multirow{2}{*}{ Days week } & \multicolumn{2}{c}{ Quantitative indicators of MP } & \multicolumn{2}{c}{ Qualitative indicators of MP } \\
\cline { 2 - 5 } & Boys & Girls & Boys & Girls \\
\hline Monday & $123,4 \pm 5,9$ & $136,2 \pm 6,4$ & $20,3 \pm 1,7$ & $13,4 \pm 1,5$ \\
\hline Tuesday & $123,3 \pm 6,4^{*}$ & $139 \pm 6,0^{*}$ & $17,7 \pm 1,8$ & 1,3 \\
\hline Wednesday & $111,7 \pm 6,8^{*}$ & $143,6 \pm 7,5^{*}$ & $1,2 \pm 1,4$ & $11 \pm 1,8$ \\
\hline Thursday & $125,7 \pm 9,1^{*}$ & $161,7 \pm 8,2^{*}$ & $13,3 \pm 2,3$ & $10,4 \pm 1,3^{*}$ \\
\hline Friday & $106 \pm 6,6^{*}$ & $136,3 \pm 7,2^{*}$ & $16,1 \pm 1,8^{*}$ & $16,5 \pm 0,8$ \\
\hline
\end{tabular}

${ }^{*} p<0,05-0,001$ the difference between the indicators of MP boys and girls;

$\cdot p<0,05-0,001$ the difference in MP during the week

differences were found between girls and boys during the school year.

Mental performance (MP) is one of the important criteria of the state of health of schoolchildren, which characterizes the relationship between the functional state of the child's body and the educational load [18]. Therefore, in the second stage, we studied mental performance in the dynamics of the week at the beginning and end of the year.

The quantitative and qualitative component of MP was analyzed on the basis of the average number of traced signs and standardized by 500 signs of errors after each lesson, during the school day and week. On the basis of a comprehensive assessment of the work performed, the levels of working capacity of students and shifts in working capacity, which characterize the dynamics of the functional state of the nervous system [16-18]. The level and direction of changes in performance in the learning process is also assessed using "performance curves". The obtained data allow to assess the compliance of the study load with the age and functional characteristics of students.

Analysis of data on the mental capacity of first-graders showed that the dynamics of the week among boys the number of traced signs increased from $(120.5 \pm 2.6)$ to $(122.3 \pm 4.8)$ signs, $(\mathrm{p}>0.05)$ by the end of the week, and had the largest number of signs on Wednesday (127.4 \pm 4.2) but had no significant difference (Table I).

Among the girls of the second class there was a significant positive dynamics of increasing productivity during the week at the beginning of the week from $(121.0 \pm 3.0)$ to $(135.6 \pm$ $4.8)$ signs, $(\mathrm{p}<0.001)$ by the end of the week, but the largest number signs was observed on Thursday (137.2 \pm 5.1$)$. That is, for boys, starting from Wednesday, the quantitative component of MP tended to decrease, and for girls - to increase. This is confirmed by the discovery of a significant difference in the quantitative component between boys (120.6 \pm 4.8 ; $122.3 \pm 4.8)$ signs and girls $(137.2 \pm 5.1 ; 135.6 \pm 4.8)$ signs on Thursday and Friday $(\mathrm{p}<0.05)$, indicating the accumulation of fatigue in boys at the end of the week

Analyzing the qualitative indicators of MP at the end of the year, it was found that the quality of work was higher among girls on Tuesday $(12.6 \pm 0.2)$ against $(15.3 \pm 0.9)$ error, $(\mathrm{p}<0.05)$ and Friday $(11,6 \pm 0.7)$ versus $(14.8 \pm 0.8)$ error, $(p<0.05)$. Among boys and girls at the end of the week the quality of work increased from the beginning to the end of the week $(16.5 \pm 0.9)$ to $(14.4 \pm 0.8)$ error, ( $p$ $<0.05)$ among boys and from $(15.7 \pm 0.9)$ to $(11.6 \pm 0.7)$, errors $(\mathrm{p}<0.001)$ (Table II).

A detailed examination of individual classes separately revealed a significant difference in the quantitative component of MP between boys and girls. On all days of the week, except Monday at the end of the year, girls observed more signs with a significant $(\mathrm{p}<0.001)$ difference.

\section{DISCUSSION}

It is widely recognized that if pupils are to maximize their potential from schooling they will need the full support of their parents. Parental involvement refers to a broad range of activities as indicated earlier. Understanding the impact of various forms of spontaneous involvement and of the 
large range of intervention studies on achievement and adjustment must proceed in recognition of all the many factors which impinge on school outcomes. Researchers also note differences in the adaptation mechanisms in children depending on gender. Sexual differentiation is of particular importance in preschool and primary school ages and plays a huge role in the process of socialization of the child's personality, in particular in his gender identification and the formation of a sexual social role in the process of adaptation to the environment, including school [8]. According to a number of researchers, the adaptation processes are influenced by a number of factors associated with the characteristics of the nervous system of children. The mobility and immaturity of some mental processes, as well as their influence on adaptation in children of different sexes, have not been sufficiently studied $[4 ; 6 ; 8]$. Our study confirms that Biological aspects of adaptation mechanisms in girls and boys of primary school differ depending on sex and time.

\section{CONCLUSIONS}

1. Biological aspects of adaptation mechanisms in girls and boys of primary school differ depending on sex and time.

2. At the end of the school year, students demonstrate a more mature type of response to mental stress (arithmetic) than at the beginning of the year, which can be considered as a psychophysiological indicator of adaptation to learning activities. At the same time, the "physiological cost" of this adaptation was higher in girls than in boys.

3. Mental performance indicators in the dynamics of the week at the beginning of the year and at the end of the year in girls were better than in boys. At the beginning of the year, there was no significant difference between boys and girls from Monday to Thursday, boys made more mistakes on Friday. At the end of the year, boys made more mistakes than girls on Tuesday.

4. Preventive measures such as sleep and rest, walks in the fresh air aimed at promoting health can be the same for both girls and boys, but more attention and control over the implementation of these measures should be paid to boys.

\section{REFERENCES}

1. Baranov A.A., Kuchma V.R., Sukhareva L.M. New approaches to preventive and health-improving work in educational institutions: a guide for doctors. Moscow. 2008; 432.

2. Prabhuswamy M. To go or not to go: School refusal and its clinical correlates. Journal of Paediatrics and Child Health. 2018:54(10):1117-20.

3. Kuchma V.R. Hygienic problems of the organization of training in specialized classes of colleges. Hygiene and sanitation. 2015;4(87):8-10.

4. Inglés C.J., Gonzálvez C., García-Fernández J.M.et al. Current status of research on school refusal. European Journal of Educational Psychology. 2015;8:37-52.

5. Kwon D.H. Relationship among growth mindset, future time perspective, grit and procrastination. Asian Journal of Education. 2018;19(3):725-744.

6. Ivanova I.V., Chernaya N.L., Senyagina E.I. Health status and sociopsychological characteristics of schoolchildren of different types, Russian Pediatric Journal. 2010;2:53-55.
7. Park D., Yu A., Metz S.E.et al. Beliefs about stress attenuate the relation among adverse life events, perceived distress, and self-control. Child Development. 2018;89(6):2059-69.

8. Gavrilova Yu.A., Isahanov A.L., Erofeeva A.G. Sex differences of physiological and psychologic adaptation of the boys and the girls of the primary school age in psychological hygienic aspect, Modern Problems of Science and Education. Surgery. 2017;3:57-62.

9. Alexander K.L., Entwisle D.R., Kabbani N.S. The dropout process in life course perspective: Early risk factors at home and school. Teachers College Record. 2001;103(5):760-822.

10. Park M.-H., Yim H.-W., Park S.et al. School refusal behavior in South Korean first graders: A prospective observational community-based study. Psychiatry Research. 2015;227:160-65.

11. Podrigalo L.V., lermakov S.S., Avdiievska 0.G.et al. Special aspects of Ukrainian schoolchildren's eating behavior, Pedagogics, psychology, medical-biological problems of physical training and sports. 2017;3:198-206.

12. McNeal R.B. Parental involvement as social capital: Differential effectiveness on science achievement, truancy, and dropping out, Social Forces. 1999;78 (1):117-44.

13. Danylenko H., Shcherbakova 0., Avdiievska 0. Healthcare and psychological features of adolescent's personal development in the modern family, Ukraine. Nation's Health. 2020;4. http://healty-nation. uzhnu.edu.ua/article/view/220382.

14. Danilenko H.M., Avdievska O.H., Holubnicha H.I. Objective and subjective assessment of the health primary school age children, IV International Congress of the Polish Society of Public Health, Public Health Forum, 22-23 November 2018. Wrocław, Poland. 2018;3(46):198.

15. Andermo S., Hellénius M.L., Lidin M. et al. Effectiveness of a family intervention on health related quality of life a healthy generation, a controlled pilot trial, BMC Public Health. 2020;20(1):809.

16. Gasser T., Von Lucadou-Müller I., Verleger R., Bächer P. Correlating EEG and IQ: A new look at an old problem using computerised EEG parameter, EEG and Clinical Neuropsysiology. 1983; 55: 493-504.

17. Mayorov 0.Yu, Baevsky R. M. Application of Space Technologies For Valuation of A Stress Level. Medical Informatics Europe' 99 . I0S Press. 1999; 352-56. doi: 10.3233/978-1-60750-912-7-352.

18. Ustin T.B., Sartorius N. Mental Illness in General Health Care: An International Study, Wiley \& Sons. 1995; 410.

19. Mayorov 0.Yu. Some methodical and methodological approaches to the mathematical analysis of heart rate in conditions of emotionally intense activity and emotional stress. Health diagnostics. Proc. Plenum of the Problem Commission AMS"Mechanisms of the syst. organiz. of physiol. functions", Kursk: VSU Publ. 1990; 137-145.

20. Mayorov 0 . Yu. Searching for methods for quantitative assessment of individual resistance to emotional stress in the norm and in pathology based on the analysis of heart rate variability. Factor model. J. Klin. inform. telemed. 2017; 12(13): 53-63.

Work was performed in the State Institution "Institute of Child and Adolescent Health of the National Academy of Medical Sciences of Ukraine" within the research work № 0115 U001017 "Develop a system of preventive measures to optimize the educational activities of academically able children during their adaptation to primary school under meritocratic education ", according to the agreement of the National Academy of Medical Sciences of Ukraine. 


\section{ORCID and contributionship:}

Heorhii M. Danylenko: 0000-0001-7086-2720 A,B, F

Leonid V. Podrigalo: 0000-0002-7893-524 ${ }^{E, F}$

Olena H. Avdiievska: 0000-0001-5764-5254 B,C,D

Iryna V. Redka: 0000-0002-9620-9452 ${ }^{B, C, D}$

Oksana Ya. Mykhalchuk: 0000-0001-9628-4754 ${ }^{\text {B, }}$

\section{Conflict of interest:}

The Authors declare no conflict of interest.

\section{CORRESPONDING AUTHOR}

Olena H. Avdiievska

V.N. Karazin Kharkiv National University,

6 Svobody Square, 61006 Kharkiv, Ukraine

tel: +380506682740

e-mail: olenaavdiievska@gmail.com

Received: 22.12.2020

Accepted: 31.03 .2021

A - Work concept and design, B - Data collection and analysis, C - Responsibility for statistical analysis,

$\mathbf{D}$-Writing the article, $\mathbf{E}$-Critical review, $\mathbf{F}$ - Final approval of the article 